\title{
Assessment of chronological lifespan dependent molecular damages in yeast lacking mitochondrial antioxidant genes
}

\author{
Ayse Banu Demir, Ahmet Koc* \\ Department of Molecular Biology and Genetics, Izmir Institute of Technology, 35430 Urla, Izmir, Turkey
}

\section{A R T I C L E I N F O}

\section{Article history:}

Received 4 August 2010

Available online 11 August 2010

\section{Keywords:}

Chronological aging

Molecular damage

Mitochondria

Antioxidant gene

Oxidative stress

\begin{abstract}
A B S T R A C T
The free radical theory of aging states that oxidative damage to biomolecules causes aging and that antioxidants neutralize free radicals and thus decelerate aging. Mitochondria produce most of the reactive oxygen species, but at the same time have many antioxidant enzymes providing protection from these oxidants. Expecting that cells without mitochondrial antioxidant genes would accumulate higher levels of oxidative damage and, therefore, will have a shorter lifespan, we analyzed oxidative damages to biomolecules in young and chronologically aged mutants lacking the mitochondrial antioxidant genes: GRX2, CCP1, SOD1, GLO4, TRR2, TRX3, CCS1, SOD2, GRX5, and PRX1. Among these mutants, ccp1 1 , trx3 $\Delta$, $\operatorname{grx} 5 \Delta, \operatorname{prx} 1 \Delta$, mutants were sensitive to diamide, and $\operatorname{ccs} 1 \Delta$ and $\operatorname{sod} 2 \Delta$ were sensitive to both diamide and menadione. Most of the mutants were less viable in stationary phase. Chronologically aged cells produced higher amount of superoxide radical and accumulated higher levels of oxidative damages. Even though our results support the findings that old cells harbor higher amount of molecular damages, no significant difference was observed between wild type and mutant cells in terms of their damage content. (c) 2010 Elsevier Inc. All rights reserved.
\end{abstract}

\section{Introduction}

Many essential biological processes such as apoptosis, calcium homeostasis, ATP production, as well as many anabolic and catabolic reactions take place in the mitochondria. During aerobic respiration, some of the oxygen taken up by mitochondria is converted to superoxide radicals [1] that initiate the formation of a series of reactive oxygen species which damage cellular components.

Time-dependent accumulation of biological damages is known to be important in the aging process [2]. The oxidative stress theory of aging assumes that oxidation of biomolecules is the major cause of aging [3-9]. Molecules such as DNA, proteins and lipids are under constant attack of oxidants. [5,8-14]. Since reactive oxygen species (ROS) are primarily formed in the mitochondria, understanding the specific roles of mitochondrial antioxidant genes in defense against oxidative stress is important for the assessment of their roles in the aging and age-related disorders.

Superoxide dismutases (SOD1 and SOD2) and other mitochondrial ROS scavenging enzymes such as thioredoxin (TRX3), thioredoxin reductase (TRR2), peroxiredoxin (PRX1), glutaredoxins (GRX2, GRX5), cytochrome-c peroxidase (CCP1), glyoxalase II (GLO4), and copper chaperone (CCS1) constitute the major mitochondrial defense system against oxidative stress [15]. Among

\footnotetext{
* Corresponding author. Fax: +90 2327507509

E-mail address: ahmetkoc@iyte.edu.tr (A. Koc).
}

these genes, the role of superoxide dismutases (SOD1 and SOD2) and copper chaperone (CCS1) in both replicative and chronological aging have been studied previously $[16,17]$. The effects of deletion of other mitochondrial antioxidant genes were only shown for replicative lifespan in yeast [15].

In this study, we investigate the relationship between chronological aging and oxidative damages to DNA, lipids and proteins in cells lacking mitochondrial antioxidant genes. Accumulation of molecular damage was shown to be significantly higher in chronologically aged cells when compared to young cell population, however, cells lacking mitochondrial antioxidant genes did not experience extensive molecular damages.

\section{Material and methods}

\subsection{Yeast growth and strains}

Saccharomyces cerevisiae wild type strain (BY4741) and 10 isogenic deletion mutants were obtained from yeast deletion library (Invitrogen). Yeast cells were grown in rich YPD (2\% glucose, 2\% peptone and $1 \%$ yeast extract) media.

\subsection{Chronological lifespan determination}

The chronological aging pattern of yeast cells were identified by using the colony formation unit (CFU) assay [18]. Briefly, yeast 
strains were grown in $5 \mathrm{ml}$ YPD media overnight at $30^{\circ} \mathrm{C}$ at $180 \mathrm{rpm}$. Two milliliters of overnight cultures were suspended in $25 \mathrm{ml}$ of fresh YPD in $250 \mathrm{ml}$ flasks and incubated at $30^{\circ} \mathrm{C}$ at $200 \mathrm{rpm}$ for 15 days. During this period, a number of cells were taken and plated on YPD-agar media every $72 \mathrm{~h}$ to measure the survival rate of the cells. Each sample was analyzed three times.

\subsection{Determination of protein carbonylation and lipid peroxidation levels}

Cells were pelleted, washed with $\mathrm{dH}_{2} \mathrm{O}$ twice and resuspended in a mixture of $1 \mathrm{ml}$ of PBS (phosphate buffer saline), $500 \mu$ l glass beads, $50 \mu$ of $100 \mathrm{mM}$ PMSF (phenylmethylsulfonylfluoride) and $10 \mu \mathrm{l}$ of $0.5 \mathrm{M}$ BHT (butylated hydroxytoluene). Samples were vortexed for $10 \mathrm{~min}$ and kept cold. After spinning down at $3000 \mathrm{rpm}$ for $3 \mathrm{~min}$, supernatants were analyzed for their protein contents by Bradford assay [19] and stored at $-80^{\circ} \mathrm{C}$ until further analyses. For the protein carbonylation, DNPH (2,4-dinitrophenylhydrazine) assay [8] was used.

To determine the lipid peroxidation of cells, BIOXYTECH ${ }^{\circledR}$ LPO$586^{\mathrm{TM}}$ colorimetric assay kit (OxisResearch, Portland, Oregon, USA) was used, which is based on the reaction of N-methyl-2-phenylindole with malondialdehyde (MDA) that yields a stable chromophore with maximum absorbance at $586 \mathrm{~nm}$.

\subsection{Determination of spontaneous genomic DNA mutation rates}

The spontaneous genomic mutation rates were determined by using the canavanine resistance assay with few modifications [20]. Briefly, overnight cultures were diluted in fresh YPD media and incubated for $6 \mathrm{~h}$. Samples were washed with $\mathrm{dH}_{2} \mathrm{O}$ twice and suspended in $500 \mu \mathrm{l} \mathrm{dH_{2 }}$ O. For each strain, $10^{7}$ cells were plated on SD-canavanine $(60 \mathrm{mg} / \mathrm{L})$ plates lacking arginine. The same amount of cells was also plated on YPD plates as the control. The cells were incubated at $30^{\circ} \mathrm{C}$ for 4 days and the colonies were counted.

\subsection{Determination of superoxide production rate}

The superoxide production rates of the yeast were measured using the fluorometric dye MitoSOX ${ }^{\mathrm{TM}}$ red (Invitrogen) as described by the manufacturer. Briefly, $\mathrm{OD}_{600}$ values of the overnight grown cells were adjusted to approximately 0.2 with fresh media. Cells were incubated for an additional $2 \mathrm{~h} \cdot 10^{7}$ cells were pelleted and resuspended in $250 \mu \mathrm{l}$ of YPD containing $5 \mu \mathrm{M}$ of MitoSOX red dye. After $1 \mathrm{~h}$ incubation at $30^{\circ} \mathrm{C}$, the samples were washed with PBS twice and analyzed by a fluorometric spectrometer (Thermo VarioScan Flash spectral scanning multimode reader).

\subsection{Determination of oxidative stress tolerances}

A spotting assay was done to observe the diamide and menadione sensitivities. Overnight grown cell cultures were serially diluted to $\mathrm{OD}_{600}$ value of $0.2,0.02,0.002$ and 0.0002 . Five microliters of each dilution was dropped on YPD plates containing $1.5,2.0$ and $2.5 \mathrm{mM}$ diamide or $0.1 \mathrm{mM}$ menadione. After 2 days of incubation, pictures of plates were taken.

\subsection{Statistical analysis}

Mann-Whitney test was applied to test the significance of biomolecular damages between the young and the aged cell populations by using the 'SPSS 15.0 for Windows Evaluation Version' Programme.

\section{Results}

\subsection{Oxidative stress tolerance}

Mitochondrial antioxidant proteins were identified by using the MitoP2 program [15], in which the mitochondrial target sequence in genes were analyzed and compared with the published experimental data in order to predict the protein localizations with a high accuracy rate [21]. Ten different proteins, Grx2, Ccp1, Sod1, Glo4, Trr2, Trx3, Ccs1, Sod2, Grx5 and Prx1, were found to reside in mitochondria and to have antioxidant properties. Previously, cells lacking these genes were shown to be sensitive to hydrogen peroxide treatment [15]. Since superoxide is produced in mitochondria at high levels, we rationalize that absence of mitochondrial antioxidant genes may result in higher sensitivity to oxidizing agents like diamide and menadione. As seen in Fig. $1 \mathrm{~A}$, all mutants except for grx $2 \Delta$ were shown to be sensitive to diamide, a thiol oxidizing agent. Surprisingly, most of the cells, excluding $\operatorname{ccs} 1 \Delta$ and $\operatorname{sod} 2 \Delta$ mutants, were only slightly sensitive to menadione, a superoxide generating agent (Fig. 1A, right panel). Among these genes, deletion of CCS1 showed the highest sensitivity to both diamide and menadione. This is inline with a previous study which also showed that $\operatorname{sod} 1 \Delta$ cells were sensitive to both menadione and diamide [22].

A

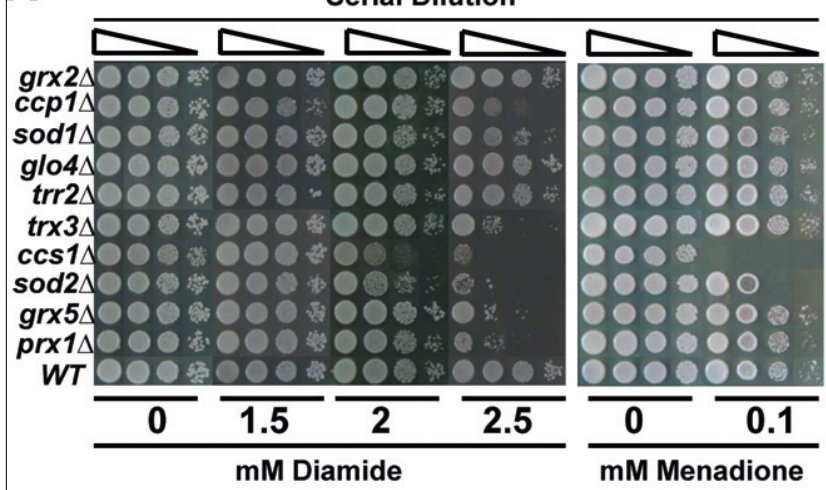

B

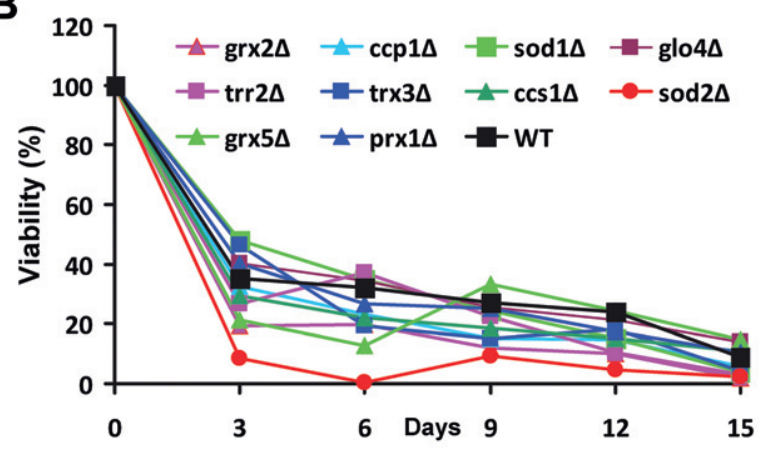

Fig. 1. Oxidative stress tolerance levels and chronological aging analyses. (A) Diamide and menadione tolerance. Cells were grown in rich media and serially diluted to $0.2,0.02,0.002,0.0002 \mathrm{OD}_{600}$. Five microliters of each cell suspension was applied to each spot and samples were incubated for three days. (B) Chronological aging patterns. Cells were grown and kept in rich (YPD) media for 15 days. Viability of cells was determined by CFU values of samples taken in every 3 days. Experiments were repeated three times and a representative figure is shown. Table in lower panel shows the mean values and standard errors of the mean for chronological aging analyses. 


\subsection{Chronological aging analyses}

The deletion of SOD1 and SOD2 or simultaneous deletion of both genes dramatically reduces chronological and replicative lifespan in yeast [17]. When cells lacking mitochondrial antioxidant genes were analyzed for replicative lifespan, absence of only SOD1, SOD2, and CCS1 genes caused a reduction in lifespan, while absence of the other genes had very little effect [15]. Here we analyzed chronological lifespan of mutants to see which antioxidant genes play roles in preserving cell viability in the stationary phase. Apart from glo $4 \Delta$ and grx $5 \Delta$ mutants, the others had lower rates of viability when compared to the wild type cells (Fig. 1B). Three mutants, trr $2 \Delta$, grx $5 \Delta$ and $\operatorname{sod} 2 \Delta$, showed an adaptive re-growth pattern, in which they had an increased rate of viability after 3 or 6 days of incubation which was followed by a decrease at later time points. The sod $2 \Delta$ mutants had the lowest rate of viability among all the mutants.

\subsection{Mitochondrial superoxide production rates}

Superoxide production rates of the mutants were monitored by using the fluorescent dye MitoSOX ${ }^{\mathrm{TM}}$ red (Invitrogen), which is oxidized in mitochondria by superoxide and exhibits red fluorescence. In young mutants (logarithmically growing cells), superoxide levels were very similar to each other and did not differ from that of wild type cells (Fig. 2). However, in old cells, superoxide levels were increased 2.5- to 16-fold when compared to the corresponding young cells. The highest amount of superoxide was detected in old $\operatorname{sod} 2 \Delta$ mutants which was 3 -fold higher than that of old wild type cells.

\subsection{Protein carbonylation and lipid peroxidation levels}

Since mitochondrial antioxidant genes are important in aging, we reasoned that cells without these genes might accumulate extensive oxidative damages which may accelerate the aging process. First, molecular damages that each mutation would cause in logarithmically growing mutants (young cells) in rich media were monitored. As seen in Fig. 3A, mutants showed no increase in their protein carbonylation levels. Similarly, their malondialdehyde (MDA), a lipid peroxidation product, levels were also not higher compared to that of wild type cells, except for the grx $2 \Delta$ mutant in which MDA level increased 2-fold (Fig. 3B). Thus, deletion of most of the mitochondrial antioxidant genes did not result in accumulation of oxidized protein and lipid products, and many mutants had even lower levels of molecular damage in their young stage. Next, we asked whether chronologically aged cells accumulate more damages than the young ones and how elimination of the antioxidant genes affects the damage profiles of the cells. As shown in Fig. 3A and B as dark bars, levels of both protein carbonylation

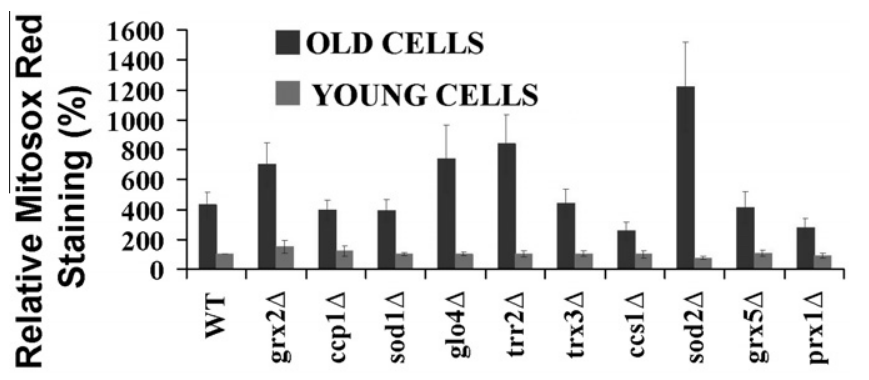

Fig. 2. Superoxide production rates. Young (logarithmically growing) and old (15 day-old stationary phase) cells were stained by MitoSOX red dye and analyzed by a fluorescent spectrophotometer. The relative values of samples were adjusted by the value of young wild type cells, which was taken as $100 \%$. Measurements were performed three times and bars show the standard deviations of the means.
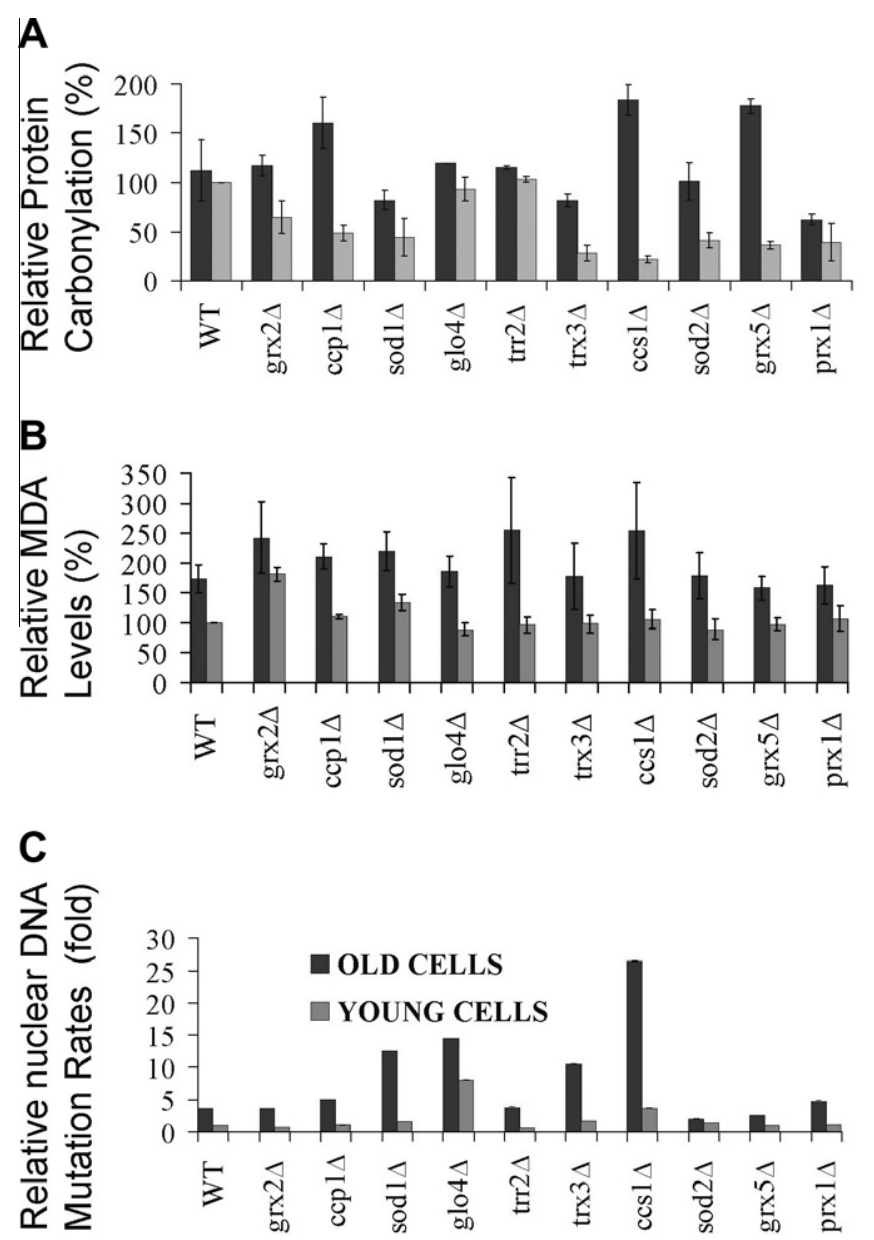

Fig. 3. Comparison of oxidative molecular damages in cells. (A) Protein carbonylation levels. (B) Lipid peroxidation product (MDA) levels. (C) Spontaneous DNA mutation rates of the cells as detected by canavanine resistance. The relative values of samples were adjusted by the value of young wild type cells, which was taken as $100 \%$.

and lipid peroxidation products were significantly higher in old cells when compared to those of young cells that are shown as open bars $(p<0001)$. Old $\operatorname{ccs} 1 \Delta$, grx $5 \Delta$ and $\operatorname{ccp} 1 \Delta$ strains showed the highest increase in their carbonyl contents, which were $71 \%$, $65 \%$ and $48 \%$ more than that of wild type cells, respectively. For MDA content, grx $2 \Delta$, trr $2 \Delta$ and $\operatorname{ccs} 1 \Delta$ mutants had slightly higher levels compared to that of wild type cells.

\subsection{Spontaneous nuclear DNA mutation rates}

We also investigated forward mutation rates of the antioxidant mutants in both young and old stages. Young and old cells were forced to grow in the presence of canavanine, which is a competitive inhibitor of arginine permease that is encoded by the CAN1 locus. Cells that gain mutations in CAN1 locus could grow on this media. Absence of glo $4 \Delta$ and $\operatorname{ccs} 1 \Delta$ lead to an 8- and a 4 -fold increase in spontaneous mutation rates in young cells, respectively (Fig. 3C). All analyzed aged cells showed significant genomic instability. Old wild type cells showed a 4-fold and mutants showed a 2to 26 -fold increase in their spontaneous mutation rates.

\section{Discussion}

Several studies reported that deletion or overexpression of antioxidant genes (e.g., SOD1, SOD2, CTT1, MXR1) can modulate the lifespan of yeast cells [15-17,23]. Decreased or increased ROS 
scavenging activity does not always affect the lifespan of organisms in a predictable manner. A recent study has shown that deletion of SOD2 in Caenorhabditis elegans extends lifespan, but deletion of other SODs has no effect on lifespan [14]. Overexpression of Mn-SOD in human cells resulted in a cell cycle arrest and subsequent accumulation of intracellular hydrogen peroxide, which lead to a shorter lifespan [24]. Similarly, overexpression of $\mathrm{Cu}-\mathrm{Zn}$ dependent SOD gene has been shown not to extend the lifespan of Drosophila [25]. On the other hand, deletion of SOD1, SOD2 and CCS1 genes decreased the replicative or chronological lifespan of yeast, however, deletion of the other mitochondrial antioxidant genes had little or no effects $[15,16]$. The aim of this study was to investigate the effects of different mitochondrial antioxidant genes within the context of chronological lifespan and chronological lifespan dependent damages in yeast. Here, it is shown that the macromolecular oxidative damage as observed in accumulation of lipid peroxidation, protein carbonylation and spontaneous DNA mutations increases as aging progresses. However, individual antioxidant genes were found to have little importance in preventing accumulation of molecular damages during the chronological aging process.

When the oxidative stress sensitivity of cells were analyzed for diamide and menadione, sod $2 \Delta$ and $\operatorname{ccs} 1 \Delta$ mutants were found to be the two strains that were most dramatically affected by the presence of both agents. In addition to that, $\operatorname{sod} 2 \Delta$ and $\operatorname{ccs} 1 \Delta$ cells, $\operatorname{ccp} 1 \Delta, \operatorname{sod} 1 \Delta, \operatorname{tr} \times 3 \Delta, \operatorname{gr} x 5 \Delta$, and prx $1 \Delta$ mutants were also found to be sensitive to diamide (Fig. 1 ). In parallel to their sensitivity to oxidants, these cells had a lower viability rate in the stationary phase (Fig. 2A) which is in line with the oxidative stress theory of aging. However, none of the mutants had a significantly higher amount of superoxide radical in the logarithmically growing state (Fig. 2). Consistent with their low superoxide contents, logarithmically growing mutants did not have elevated levels of oxidative protein and lipid damages. Nevertheless, deletion of GLO4 and CCS1 resulted in higher rates of spontaneous genomic DNA mutations. In stationary phase (old) cells, however, the extent of both protein oxidation and lipid peroxidation products was significantly higher in the mutants and wild type when compared to the logarithmically growing (young) cells (Fig. 3). The superoxide levels were also higher in old cells compared to young cells which supports the finding that superoxide production levels increase upon aging [26]. Thus, our results are consistent with the idea that cells produce more ROS and accumulate more oxidative damages as they get age.

Genomic instability and the rate at which genomic instability occurs have been shown to increase during aging [27-30]. Our results also show that the rate of spontaneous mutations was higher in old cells, especially for $\operatorname{sod} 1 \Delta, \operatorname{ccs} 1 \Delta$, and glo4 $\Delta$ strains (Fig. 3C).

Deletion of the CCS1 gene, which encodes for a copper chaperone for Sod1, resulted in high sensitivity to reactive oxygen species, as well as a significant increase in protein carbonylation, lipid peroxidation, and genomic instability. Therefore, CCS1 seems to be one of the most important mitochondrial antioxidant genes in the chronological aging process. However, Ccs1 is not strictly necessary for Sod1p function since Sod1p can supply its copper in a Ccs1-independent manner [31]. Thus, the importance of CCS1 gene in aging could be because of its roles in providing copper to other proteins such as Cox11 rather than Sod1 [32].

Deletion of the GLO4 gene increased the rate of spontaneous nuclear DNA mutations, which indicates that the glyoxylase-II enzyme is important in maintaining genome stability. The functions of glyoxalases were proposed to be important in genome stability and other cellular damages because of their scavenging activity of cytotoxic methylglyoxal, which is a byproduct of glycolysis [33,34]. Glycation reactions of methylglyoxal with amino acids can induce oxidative stress [35]. Therefore, methlyglyoxal dependent ROS production could be the basis of high rate of spontaneous DNA mutations observed in glo4s cells. In addition to genomic instability, glo4 $\Delta$ mutants also showed a 275 -fold increase in their spontaneous mitochondrial DNA mutation rate as measured by an erythromycin resistance assay (unpublished data) which supports the idea that Glo4 is important in preserving genome stability.

There could be many reasons why deletion of mitochondrial antioxidant genes did not result in extensive molecular damages in our analyses. First, up regulation of oxidative stress response pathways in the absence of antioxidant genes might compensate the deficiency. This type of regulation has shown to be important in oxidative stress tolerance pathways [36,37]. Second, yeast cells have many antioxidant genes with overlapping functions such as SODs and GRXs, in the case of mitochondria, and the absence of one of these redundant genes could be tolerated by their functional counterparts. Therefore, deletion of a single antioxidant gene may not result in a significant outcome in many aspects of oxidative stress tolerance.

Our results show that chronologically aged cells produce higher amount of superoxide radical and harbor extensive oxidative damages to proteins, lipids and DNA. However, the roles of individual mitochondrial antioxidant genes in protecting cells from these damages may not always be in favor of the oxidative stress theory of aging.

\section{Acknowledgment}

We would like to thank to the Izmir Institute of Technology, Biotechnology and Bioengineering Central Research Laboratories and Mass Spectra Core Facilities for their technical support. Also we would like to thank to Dr. Türkan GÜNAY (Dokuz Eylul University, School of Medicine) for her help in statistical analysis. This work was supported by the Turkish Academy of Science GEBIP and the DPT 2003K120690 grants to AK.

\section{References}

[1] J.M. McCord, I. Fridovich, The utility of superoxide dismutase in studying free radical reactions. I. Radicals generated by the interaction of sulfite, dimethyl sulfoxide, and oxygen, J. Biol. Chem. 244 (1969) 6056-6063.

[2] V.D. Longo, J. Mitteldorf, V.P. Skulachev, Programmed and altruistic ageing, Nat. Rev. Genet. 6 (2005) 866-872.

[3] A.P. Wickens, Ageing and the free radical theory, Respir. Physiol. 128 (2001) 379-391.

[4] J.E. Klaunig, L.M. Kamendulis, The role of oxidative stress in carcinogenesis, Annu. Rev. Pharmacol. Toxicol. 44 (2004) 239-267.

[5] C.C. Winterbourn, Reconciling the chemistry and biology of reactive oxygen species, Nat. Chem. Biol. 4 (2008) 278-286.

[6] E. Herrero, J. Ros, G. Belli, E. Cabiscol, Redox control and oxidative stress in yeast cells, Biochim. Biophys. Acta 1780 (2008) 1217-1235.

[7] N.A. Doudican, B. Song, G.S. Shadel, P.W. Doetsch, Oxidative DNA damage causes mitochondrial genomic instability in Saccharomyces cerevisiae, Mol. Cell. Biol. 25 (2005) 5196-5204.

[8] I. Dalle-Donne, R. Rossi, D. Giustarini, A. Milzani, R. Colombo, Protein carbonyl groups as biomarkers of oxidative stress, Clin. Chim. Acta 329 (2003) 23-38.

[9] D. Pratico, Lipid peroxidation and the aging process, Sci. Aging Knowledge Environ. 2002 (2002) re5.

[10] W.C. Burhans, M. Weinberger, DNA replication stress, genome instability and aging, Nucleic Acids Res. 35 (2007) 7545-7556.

[11] B.D. Harfe, S. Jinks-Robertson, DNA mismatch repair and genetic instability, Annu. Rev. Genet. 34 (2000) 359-399.

[12] Q. Chen, Q. Ding, J.N. Keller, The stationary phase model of aging in yeast for the study of oxidative stress and age-related neurodegeneration, Biogerontology 6 (2005) 1-13.

[13] E.R. Stadtman, R.L. Levine, Protein oxidation, Ann. NY Acad. Sci. 899 (2000) 191-208.

[14] J.M. Van Raamsdonk, S. Hekimi, Deletion of the mitochondrial superoxide dismutase sod-2 extends lifespan in Caenorhabditis elegans, PLoS Genet. 5 (2009) e1000361.

[15] E.S. Unlu, A. Koc, Effects of deleting mitochondrial antioxidant genes on life span, Ann. NY Acad. Sci. 1100 (2007) 505-509.

[16] N. Harris, M. Bachler, V. Costa, M. Mollapour, P. Moradas-Ferreira, P.W. Piper, Overexpressed Sod1p acts either to reduce or to increase the life spans and 
stress resistance of yeast, depending on whether it is $\mathrm{Cu}(2+)$-deficient or an active $\mathrm{Cu}, \mathrm{Zn}$-superoxide dismutase, Aging Cell 4 (2005) 41-52.

[17] V.D. Longo, E.B. Gralla, J.S. Valentine, Superoxide dismutase activity is essential for stationary phase survival in Saccharomyces cerevisiae. Mitochondrial production of toxic oxygen species in vivo, J. Biol. Chem. 271 (1996) 1227512280.

[18] E. Parrella, V.D. Longo, The chronological life span of Saccharomyces cerevisiae to study mitochondrial dysfunction and disease, Methods 46 (2008) 256-262.

[19] M.M. Bradford, A rapid and sensitive method for the quantitation of microgram quantities of protein utilizing the principle of protein-dye binding, Anal. Biochem. 72 (1976) 248-254.

[20] Z. Sobol, N.M. Cook, R.H. Schiestl, HNO induces DNA deletions in the yeast $S$. cerevisiae, Mutat. Res. 638 (2008) 83-89.

[21] C. Andreoli, H. Prokisch, K. Hortnagel, J.C. Mueller, M. Munsterkotter, C. Scharfe, T. Meitinger, MitoP2, an integrated database on mitochondrial proteins in yeast and man, Nucleic Acids Res. 32 (2004) D459-462.

[22] G.W. Thorpe, C.S. Fong, N. Alic, V.J. Higgins, I.W. Dawes, Cells have distinct mechanisms to maintain protection against different reactive oxygen species: oxidative-stress-response genes, Proc. Natl. Acad. Sci. USA 101 (2004) 65646569.

[23] A. Koc, A.P. Gasch, J.C. Rutherford, H.Y. Kim, V.N. Gladyshev, Methionine sulfoxide reductase regulation of yeast lifespan reveals reactive oxygen species-dependent and -independent components of aging, Proc. Natl. Acad. Sci. USA 101 (2004) 7999-8004.

[24] Y.H. Wei, H.C. Lee, Oxidative stress, mitochondrial DNA mutation, and impairment of antioxidant enzymes in aging, Exp. Biol. Med. (Maywood) 227 (2002) 671-682.

[25] W.C. Orr, R.J. Mockett, J.J. Benes, R.S. Sohal, Effects of overexpression of copper-zinc and manganese superoxide dismutases, catalase, and thioredoxin reductase genes on longevity in Drosophila melanogaster, J. Biol. Chem. 278 (2003) 26418-26422

[26] R.S. Sohal, H.H. Ku, S. Agarwal, M.J. Forster, H. Lal, Oxidative damage, mitochondrial oxidant generation and antioxidant defenses during aging and in response to food restriction in the mouse, Mech. Ageing Dev. 74 (1994) 121133.
[27] M.A. McMurray, D.E. Gottschling, An age-induced switch to a hyperrecombinational state, Science 301 (2003) 1908-1911.

[28] P. Fabrizio, L. Li, V.D. Longo, Analysis of gene expression profile in yeast aging chronologically, Mech. Ageing Dev. 126 (2005) 11-16.

[29] P. Fabrizio, L. Battistella, R. Vardavas, C. Gattazzo, L.L. Liou, A. Diaspro, J.W. Dossen, E.B. Gralla, V.D. Longo, Superoxide is a mediator of an altruistic aging program in Saccharomyces cerevisiae, J. Cell. Biol. 166 (2004) 1055-1067.

[30] F. Madia, M. Wei, V. Yuan, J. Hu, C. Gattazzo, P. Pham, M.F. Goodman, V.D. Longo Oncogene homologue Sch9 promotes age-dependent mutations by a superoxide and Rev1/Polzeta-dependent mechanism, J. Cell. Biol. 186 (2009) 509-523.

[31] J.M. Leitch, L.T. Jensen, S.D. Bouldin, C.E. Outten, P.J. Hart, V.C. Culotta Activation of $\mathrm{Cu}, \mathrm{Zn}$-superoxide dismutase in the absence of oxygen and the copper chaperone CCS, J. Biol. Chem. 284 (2009) 21863-21871.

[32] C.Q. Scheckhuber, J. Grief, E. Boilan, K. Luce, F. Debacq-Chainiaux, C. Rittmeyer, R. Gredilla, B.O. Kolbesen, O. Toussaint, H.D. Osiewacz, Age-related cellula copper dynamics in the fungal ageing model Podospora anserina and in ageing human fibroblasts, PLoS One 4 (2009) e4919.

[33] W.B. Bair 3rd, C.M. Cabello, K. Uchida, A.S. Bause, G.T. Wondrak, GLO1 overexpression in human malignant melanoma, Melanoma Res. 20 (2010) 8596.

[34] A. Bito, M. Haider, I. Hadler, M. Breitenbach, Identification and phenotypic analysis of two glyoxalase II encoding genes from Saccharomyces cerevisiae GLO2 and GLO4, and intracellular localization of the corresponding proteins, J. Biol. Chem. 272 (1997) 21509-21519.

[35] W.H. Chan, H.J. Wu, N.H. Shiao, Apoptotic signaling in methylglyoxal-treated human osteoblasts involves oxidative stress, c-Jun N-terminal kinase, caspase3, and p21-activated kinase 2, J. Cell. Biochem. 100 (2007) 1056-1069.

[36] O. Carmel-Harel, R. Stearman, A.P. Gasch, D. Botstein, P.O. Brown, G. Storz, Role of thioredoxin reductase in the Yap1p-dependent response to oxidative stress in Saccharomyces cerevisiae, Mol. Microbiol. 39 (2001) 595-605.

[37] T.W. O'Rourke, N.A. Doudican, M.D. Mackereth, P.W. Doetsch, G.S. Shadel, Mitochondrial dysfunction due to oxidative mitochondrial DNA damage is reduced through cooperative actions of diverse proteins, Mol. Cell. Biol. 22 (2002) 4086-4093. 